\title{
The referential grain size and effective porosity in the Kozeny-Carman model
}

\author{
Kosta Urumović ${ }^{1}$ and Kosta Urumović $\mathrm{Sr}^{2}$ \\ ${ }^{1}$ Croatian Geological Survey, Sachsova 2, P.O. Box 268, 10001 Zagreb, Croatia \\ ${ }^{2}$ Ulica Lea Müllera 3. odvojak 2, 10090 Zagreb, Croatia \\ Correspondence to: Kosta Urumović (kosta.urumovic@ hgi-cgs.hr)
}

Received: 4 December 2015 - Published in Hydrol. Earth Syst. Sci. Discuss.: 18 January 2016

Revised: 5 April 2016 - Accepted: 9 April 2016 - Published: 3 May 2016

\begin{abstract}
In this paper, the results of permeability and specific surface area analyses as functions of granulometric composition of various sediments (from silty clays to very well graded gravels) are presented. The effective porosity and the referential grain size are presented as fundamental granulometric parameters expressing an effect of the forces operating on fluid movement through the saturated porous media. This paper suggests procedures for calculating referential grain size and determining effective (flow) porosity, which result in parameters that reliably determine the specific surface area and permeability. These procedures ensure the successful application of the Kozeny-Carman model up to the limits of validity of Darcy's law. The value of effective porosity in the referential mean grain size function was calibrated within the range of $1.5 \mu \mathrm{m}$ to $6.0 \mathrm{~mm}$. The reliability of the parameters applied in the KC model was confirmed by a very high correlation between the predicted and tested hydraulic conductivity values $\left(R^{2}=0.99\right.$ for sandy and gravelly materials; $R^{2}=0.70$ for clayey-silty materials). The group representation of hydraulic conductivity (ranging from $10^{-12} \mathrm{~m} \mathrm{~s}^{-1}$ up to $10^{-2} \mathrm{~m} \mathrm{~s}^{-1}$ ) presents a coefficient of correlation of $R^{2}=0.97$ for a total of 175 samples of various deposits. These results present new developments in the research of the effective porosity, the permeability and the specific surface area distributions of porous materials. This is important because these three parameters are critical conditions for successful groundwater flow modeling and contaminant transport. Additionally, from a practical viewpoint, it is very important to identify these parameters swiftly and very accurately.
\end{abstract}

\section{Introduction}

The effect of the granulometric composition of granular porous media on its transmissivity, accumulation and suction parameters is both a permanent scientific challenge and a practical issue. In hydrogeology, particular attention is given to hydraulic conductivity. Hazen (1892) and Slichter (1902) have published widely accepted and reputable models for calculating the hydraulic conductivity of uniform sands using effective grain size. The term "effective grain", used for grain diameters in both formulae, could lead to confusion (Mavis and Wilsey, 1936). However, Hazen's formula uses $D_{10}$ (soil particle diameter where $10 \%$ of all soil particles are finer (smaller) by weight), and Slichter proposes using the mean diameter. This confusion persisted, and in recent decades grain size $D_{10}$ has been misused frequently (Kovács, 1981; Vukovic and Soro, 1992; Cheng and Chen, 2007; Odong, 2008) in formulae that actually use another effective grain size.

The usage of certain forms of mean grain size became inevitable with the development of hydraulic conductivity models that describe relations between the hydraulic conductivity and the specific surface area (Krüger, 1918; Zunker, 1920; Blake, 1922; Kozeny, 1927; Fair and Hatch, 1933). Kozeny (1927) introduced the equation of permeability for the flow model containing a bundle of capillary tubes of even length. Kozeny's permeability formula was later modified by Carman $(1937,1939)$. Carman redefined specific surface area and presented it as a conversion of mean grain size and the index of porosity and incorporated an effect of tortuosity for the flow around individual grains. The resultant form of the equation is known as the Kozeny-Carman (KC) 
equation. The verity of the $\mathrm{KC}$ formula application results is strongly dependent on the verity of effective porosity and representative grain size. Kozeny (1927) used the harmonic mean grain size of samples. Bear (1972) recommended the same grain size. Koltermann and Gorelick (1995) and Kamann et al. (2007) stated that the harmonic mean performed best in samples with high fine-grain contents. Chapuis and Aubertin (2003) proposed laboratory tests for determining the specific surface area of fine-grained materials for application in the KC formula. Several authors (Al-Tabbaa and Wood, 1987; Dolinar and Otoničar, 2007) have studied applicability of $\mathrm{KC}$ formulae for calculation of hydraulic conductivity of fine-grained materials. All of them have concluded that the $\mathrm{KC}$ model in its original form does not apply on clays. Dolinar and Otoničar (2007) have also proposed a modified form of the $\mathrm{KC}$ equation.

The objective of this article is to research the relationship between average mean grain size and effective porosity in relation to permeability and specific surface area for a wide range of grain sizes and particle uniformities in various soil samples. In the hydraulic conductivity calculations, the Kozeny-Carman equation was used to discover the algorithm for calculating the referential mean grain size. This grain size, along with effective porosity, generates a harmonious parametric concept of the impact of porous media geometrics on its transmission capacity.

\section{Study area and analyzed deposits}

For the purpose of this work, data on sandy and gravelly aquifers and clayey-silty deposits were collected. All of the study sites are located in the plains of the Republic of Croatia (CRO) (Fig. 1). The northern parts of the Republic of Croatia are covered by thick quaternary deposits with sandy and gravelly aquifers (Brkić et al., 2010). Covering aquitards are composed of silty-clayey deposits.

The analyses of non-cohesive deposits were conducted on 36 gravel test samples from 6 investigation boreholes on the Đurđevac well field (marked as GW on Fig. 1); 19 uniform sand test samples from the investigation boreholes on 2 well fields - Beli Manastir (marked as SU1) and Donji Miholjac (marked as SU2); and 28 samples of sand with laminas made of silty material from 2 investigation boreholes on two well fields - Ravnik (marked as FS/SU1) and Osijek (marked as FS/SU2). Appropriate pumping tests were conducted on the test fields to determine the average hydraulic value of aquifers.

Cohesive deposits were investigated at three sites. Soil samples from exploration boreholes (depth 1.0-30.0 m) were laboratory-tested. Analyses on granulometric composition (grain size distribution), hydraulic conductivity and Atterberg limits were conducted. On the first test field (route of the Danube, Sava Canal; marked as CI/MI1), all the aforementioned analyses were conducted for each soil sample. Sixty-

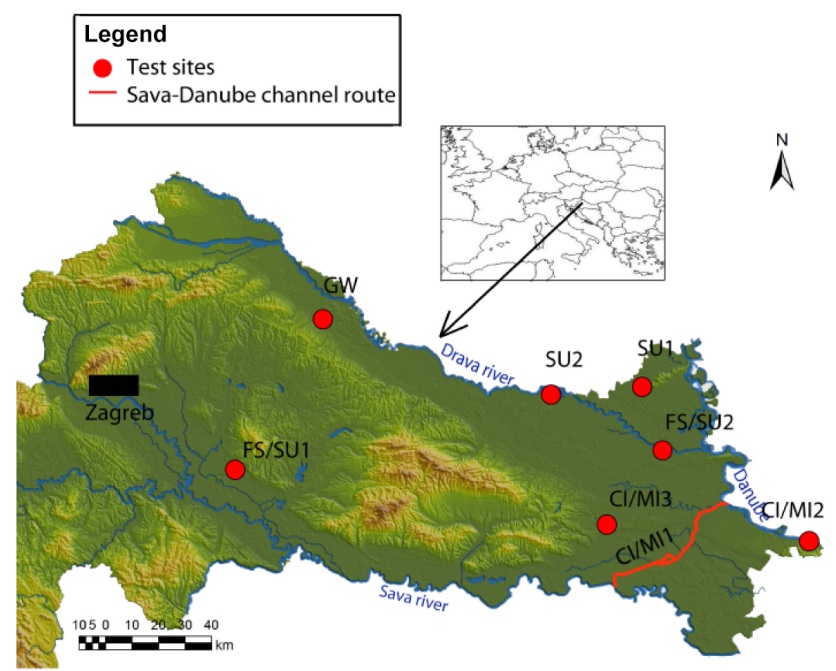

Figure 1. Map of northern Croatia with test site locations.

five samples of various soil types were analyzed. At the second and third test sites (Ilok, marked as CI/MI2, and Našice, marked as CI/MI3), loess and aquatic loess-like sediments were investigated. Laboratory analyses were conducted on 21 samples from 8 investigation boreholes. Specific analyses at various depths were conducted on the samples from this test site; on account of this, the mean values for the individual boreholes were correlated (Urumović, 2013).

\section{Methodology}

\subsection{Hydraulic model}

The effects of porosity $n$ and specific surface area $a$ on fluid movements in porous media can be illustrated by analyzing the force field in the representative elementary volume (REV) $\delta V=\delta A \delta s$ (Fig. 2) in the direction of elementary length $\delta s$, that is, perpendicular to the elementary plane $\delta A$.

The forces of pressure and gravity cause the motion of the fluid in the pores. A pressure force is transferred to $\delta s$ between the entry plane $\delta A$ and its parallel exit plane. The total amount is proportional to the gradient $\delta p / \delta s$. A component of the gravity force $\rho g$ in the fluid volume $n \delta A \delta s$ is proportional to the sine of the angle made by $\delta s$ with its projection on the horizontal plane. This equals $\rho g n \delta A \delta s \partial z / \partial s$. These two driving forces are, in fluid motion, against the force of viscosity $\tau$. The force of viscosity is proportional to the viscosity coefficient of water $\mu$, the average velocity $q_{s}$ of water flow in direction $\delta s$, and the effect of the geometry of void space, which is given by the drag resistance constant $r_{\mathrm{s}}$ in direction $\delta s$ and is proportional to the specific surface area. When the water flows, these forces are in balance, and hence 


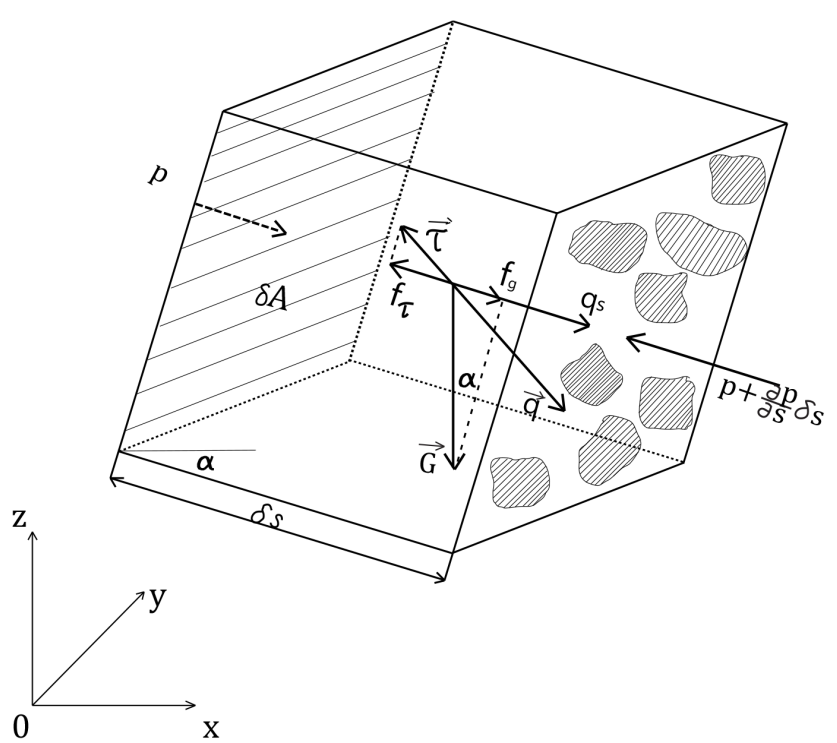

Figure 2. Definition sketch of liquid driving and opposed viscous forces for elemental volume.

(Hantush, 1964; Urumović, 2003)

$$
-n \delta V \frac{\partial p}{\partial s}-n \delta V \rho g \frac{\partial z}{\partial s}-\delta V \mu r_{\mathrm{s}} q_{s}=0
$$

or

$$
\begin{aligned}
q_{s} & =-\frac{n \rho g}{r_{\mathrm{s}} \mu} \frac{\partial(p / p \rho g+z)}{\partial s}=-\frac{n \rho g}{r_{\mathrm{s}} \mu} \frac{\partial h}{\partial s} \\
& =-K_{s} \frac{\partial h}{\partial s}=-k_{s} \frac{\rho g}{\mu} \frac{\partial h}{\partial s} .
\end{aligned}
$$

These relations express Darcy's law, as theoretically described by Hubbert (1956). Here, the focus is on permeability as a property of porous media that is (in Eq. 2) given by the relation $k_{s}=n / r_{\mathrm{s}}, k_{s}\left[L^{2}\right]$. Porosity $n$ is measured as the volume of moving fluid and is connected with the specific effect of the driving forces of pressure and gravity. The constant $r_{\mathrm{s}}$ expresses an effect of void geometry on the amount of viscosity forces and represents the extent of the effect of void geometry on water retention. The size of this effect is equivalent to a specific surface area $a_{\mathrm{p}}\left[L^{-1}\right]$ inside the porous media, that is, to a relation between (1) the surface of the solid grains that confronts the water flow and (2) the saturated void volume that transfers the flow driving force. Following the Hagen-Poiseulle law, the specific surface area $a_{\mathrm{p}}$ $\left[L^{-1}\right]$ is inversely proportional to the hydraulic radius $R_{\mathrm{H}}$ $[L]$. Thus, in an isotropic environment, $r_{\mathrm{s}} \propto a_{\mathrm{p}}^{2}$, the permeability is given as follows:

$k=\frac{n}{r_{\mathrm{s}}}=C \frac{n}{a_{\mathrm{p}}^{2}}=C n R_{\mathrm{H}}^{2}$,

where $C$ represents the dimensionless coefficient of proportionality that is dependent on the particle shape. $R_{\mathrm{H}}=1 / a_{\mathrm{p}}$ represents the hypothetical hydraulic radius of the porous media and the impact of the specific surface area of effective flow voids (Irmay, 1954).

\subsection{Geometric parameters of permeability}

There are four ways to express the specific surface area $A_{\mathrm{s}}$ $\left[L^{2}\right]$ based on solid volume, $V_{\mathrm{S}}\left[L^{3}\right]$. They are as follows:

- $a_{\mathrm{p}}\left[L^{-1}\right]-$ specific surface area based on the volume of contented pores $V_{\mathrm{p}}$;

- $a_{\mathrm{T}}\left[L^{-1}\right]-$ specific surface area based on the total volume (solids + pores) $V_{\mathrm{T}}$;

- $a_{\mathrm{m}}\left[L^{2} M^{-1}\right]-$ specific surface area based on the mass of solids $M_{\mathrm{s}}$;

- $a_{\mathrm{S}}\left[L^{-1}\right]-$ specific surface area based on the volume of solids $V_{\mathrm{s}}$ of density $\rho_{\mathrm{s}}$.

All of the above-mentioned forms of specific surface area are related to the hydraulic radius of porous media $R_{\mathrm{H}}$. The relationship between these forms is given by the following expression:

$$
\begin{aligned}
a_{\mathrm{p}} & =\frac{A_{\mathrm{s}}}{V_{\mathrm{p}}}=\frac{a_{\mathrm{T}}}{n}=\frac{\rho_{\mathrm{s}}(1-n)}{n} a_{\mathrm{m}} \\
& =\frac{(1-n)}{n} a_{\mathrm{s}}=\frac{1}{R_{\mathrm{H}}} .
\end{aligned}
$$

Kozeny (1927) used Eq. (4) with $a_{\mathrm{T}}$. He developed a theory for a bundle of capillary tubes of equal length. Carman (1937) verified the Kozeny equation and expressed the specific surface per unit mass of solid as $a_{\mathrm{m}}=A_{\mathrm{s}} / M_{\mathrm{s}}$, such that it does not vary with porosity. Furthermore, Carman (1939) tried to consider the tortuosity of the porous media by introducing an angular deviation of $45^{\circ}$ from the mean straight trajectory. He obtained the best fit from the experimental results with a factor $C=0.2$ in Eq. (3).

In hydrogeology, the specific surface area is often presented with a conversion of mean grain diameter $D_{\mathrm{m}}$. Permeability is given by the following expression (Bear, 1972):

$k=\frac{n^{3}}{180(1-n)^{2}} D_{\mathrm{m}}^{2}$.

This relation has been achieved by inserting the solid specific surface area $\left(a_{\mathrm{s}}=6 / D_{\mathrm{m}}\right)$ from Eq. (4) into Eq. (3) with $C=0.2$. This solution of the Kozeny-Carman equation (Bear, 1972) is given for uniform sphere particles. Thus, the critical factors of porous media transmissivity are effective porosity $n_{\mathrm{e}}$ (in the form of the porosity function) and referential mean grain diameter $D_{\mathrm{m}}$. Grouping these terms functionally gives the following expression:

$$
K=C \frac{n_{\mathrm{e}}}{a_{\mathrm{p}}^{2}}=\frac{n_{\mathrm{e}}}{180}\left(\frac{n_{\mathrm{e}}}{\left(1-n_{\mathrm{e}}\right)} D_{\mathrm{m}}\right)^{2} .
$$




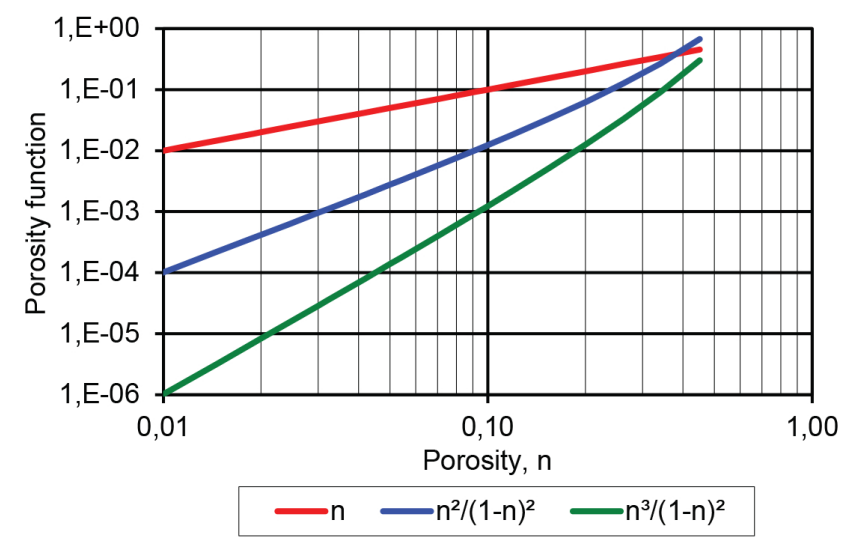

Figure 3. Effects of driving $(n)$ and drag resistance $\left(n^{2} /(1-n)^{2}\right)$ factors in the porosity function $\left(n^{3} /(1-n)^{2}\right)$.

Evidently, the effective porosity $n_{\mathrm{e}}$ has a direct impact on the magnitude of driving forces and an indirect impact as $n_{\mathrm{e}}^{2} /\left(1-n_{\mathrm{e}}\right)^{2}$ (Fig. 3) on the conversion of the specific surface value into a value of the referential mean grain diameter, which is the carrier of drag resistance. Both of the aforementioned forces affect the moving fluid. Therefore, effective porosity is an active factor only in relation to the pores through which the water flows.

\subsection{Referential grain size}

Many authors present the Kozeny-Carman equation with $D_{\mathrm{m}}^{2}$ instead of $a_{\mathrm{s}}^{2}$ in Eq. (5) without completely indicating the calculation of this equivalent mean diameter. In engineering practice, there are three ways to calculate the mean of the rated size of adjacent sieves:

Arithmetic: $\quad d_{i, \mathrm{a}}=\left(d_{i<}+d_{i>}\right) / 2$,

Geometric: $d_{i, \mathrm{~g}}=\sqrt{d_{i<} \times d_{i>}}$,

Harmonic: $\quad d_{i, \mathrm{~h}}=2 /\left[\left(1 / d_{i<}\right)+\left(1 / d_{i>}\right)\right]$,

where $d_{i<}[L]$ is the smallest grain and $d_{i>}[L]$ is the largest grain in the segment. It can be shown that $d_{i, \mathrm{~h}}<d_{i, \mathrm{~g}}<d_{i, \mathrm{a}}$ across all cases. However, the difference is not significant. Todd (1959) recommends the use of the geometric mean. Bear (1972) prefers the harmonic mean. Recent authors often follow these recommendations.

The integration of all of the mentioned grain sizes (Eqs. 79) in the sieve residue across the entire sample has a crucial effect on the mean grain size value. An overview of both the related expert and scientific literature indicates the use of either the arithmetic mean,

$D_{\mathrm{a}}=\frac{\sum P_{i} d_{i, \mathrm{a}}}{100}$,

or the harmonic mean:

$D_{\mathrm{h}}=\frac{100}{\sum\left(P_{i} / D_{i, \mathrm{~h}}\right)}$, which is the sum of mean grain sizes in sieve residue $d_{i}$. Here, $P_{i}$ is a percentile of the sieve residue mass in the total mass of the sample. Accurate results of permeability and specific surface were only achieved for the uniform deposits of sand and silt (Chapuis and Aubertin, 2003; Kasenow, 1997). Major errors resulted from applying Eqs. (10-11) for samples with a wide range of particle sizes. Similar observations were noted in sedimentology and soil science research. Arkin and Colton (1956) noted that the arithmetic mean may be significantly distorted by extreme values and therefore may not be appropriate. For soil samples, Irani and Callis (1963) advocated the use of geometric rather than arithmetic statistical properties. The reason, in part, is that in a natural soil sample there is a wide range of particle sizes making the geometrical scale much more suitable than the arithmetic scale. The general mathematical expressions for calculating the geometric particle size diameter $D_{\mathrm{g}}$ of the sample are as follows:

$D_{\mathrm{g}}=\operatorname{EXP}\left[\frac{1}{M_{\mathrm{s}}} \sum m_{i} \ln \left(d_{i, \mathrm{~g}}\right)\right]$

or

$D_{\mathrm{g}}=\operatorname{EXP}\left[0.01 \sum P_{i} \ln \left(d_{i, \mathrm{~g}}\right)\right]$,

where $M[\mathrm{M}]$ represents the mass of the sample and $m_{i}$ [M] represents the mass of particular sieve residues, $P_{i}=$ $100 \mathrm{~m}_{i} / M$. It can be shown that $D_{\mathrm{h}}<D_{\mathrm{g}}<D_{\mathrm{a}}$. This difference is very small when calculated for uniform deposits but rapidly grows when calculated for the mean grain sizes of poorly sorted deposits. In the case of gravelly sediments, the difference may reach up to 2 orders of magnitude.

\subsection{Porosity factor}

In a permeability model, the porosity function expressed by porous media transmissivity factors (Eq. 6) applies only to flow pores (Eq. 2). Accordingly, it was named effective porosity. The effective porosity could sometimes differ from the specific yield, which is a drainable porosity, determined in a laboratory. The numerical difference between the effective porosity and the specific yield may not be discernible when analyzing uniform sand, but it can increase significantly when analyzing samples containing a greater percentage of small size (clay, silt) particles. Expressions of specific yield functions of granulometric aggregates (Eckis, 1934) or median grain size (Davis and De Wiest, 1966) are unsuitable in permeability equations (Eq. 6) for two reasons. First, in these figures, specific yield was not shown in relation to referential grain size $\left(D_{\mathrm{g}}\right)$. Second, the specific yield represents the drainage in negative pressure conditions. Effective porosity represents the active pores at the time of fluid flow for a sample of certain $D_{\mathrm{g}}$, as shown in this paper. These relations were based on the analysis of data from several samples of various deposits (from clay to gravel). The initial values of porosity used in this procedure were ranges of an average 


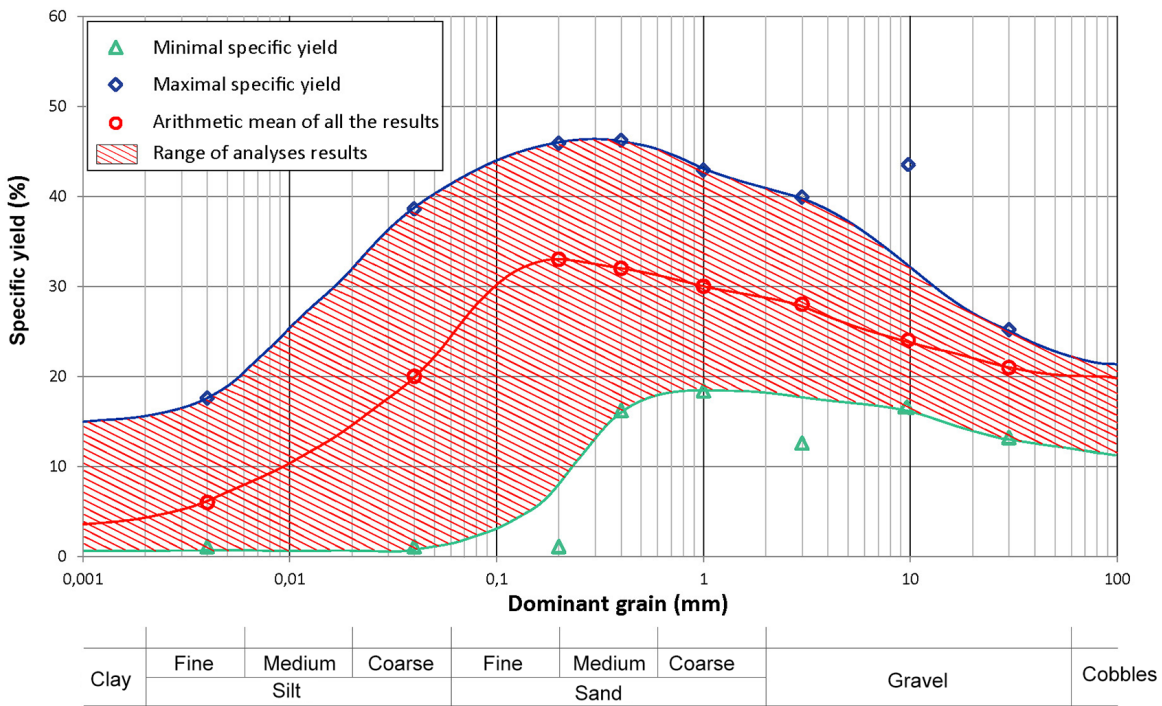

Figure 4. Range and arithmetic mean of specific yield values for 586 analyses in Hydrologic Laboratory of the USGS (from Morris and Johnson, 1967).

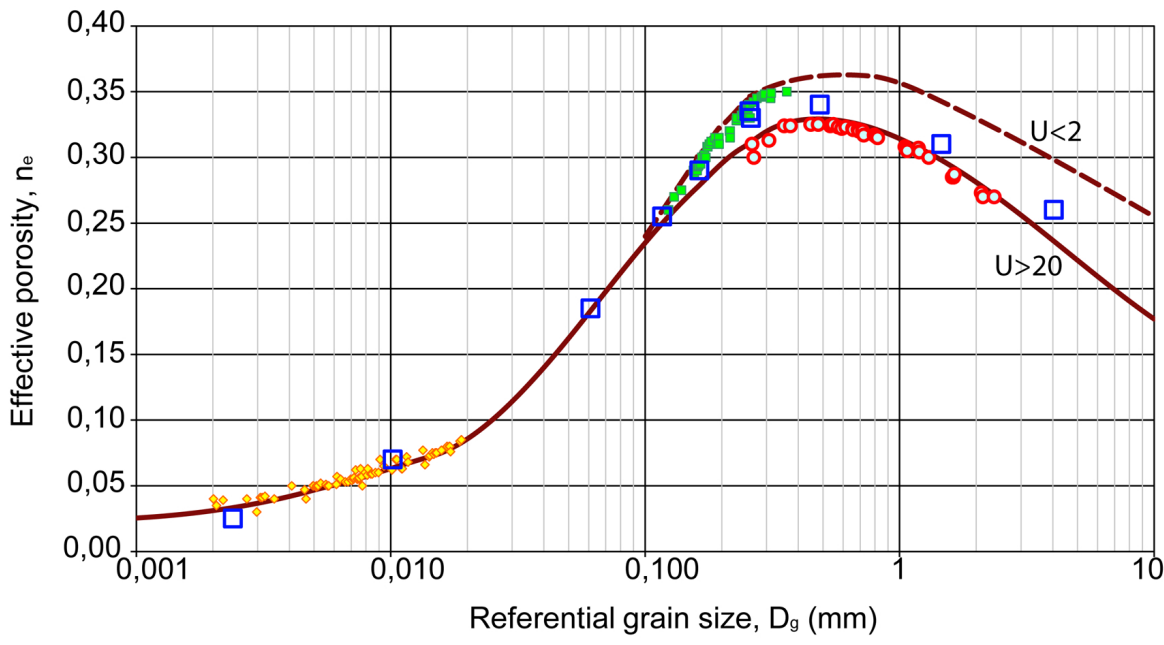

$\diamond$ Silt \& clay $\square$ Sand 0 Sandy gravel $\square$ Verification data (USGS) $-U>20-U<2$

Figure 5. Relation between referential mean grain $D_{\mathrm{g}}$ and effective porosity $n_{\mathrm{e}}$. Note: dotted line divides uniform grain deposits $U=$ $D 60 / D 10<2$ and medium uniform grain deposit $2<U<20$. Verified samples of non-uniform grain deposits of sand and gravel $(U>20)$ lie below the full line.

specific yield value (Fig. 4), according to the data from the US Geological Survey (USGS) water supply paper (Morris and Johnson, 1967). The laboratory reputation and a large number of analyses (33 samples of gravel, 287 of sand and 266 of silt and clay) provided a high-quality base for the identification of the mean value of a specific yield range.

The value of effective porosity is slightly lower than the value of the specific yield. This value is related to the referential mean grain size $\left(D_{\mathrm{g}}\right)$, forming the function of drag resistance effect in the water flow through a porous media (Eq. 6, Fig. 3). The reliable reconstruction of the effective porosity range (Fig. 5) was ensured through the strong impact of the discussed form of the porosity function $\left(n^{3} /(n-1)^{2}\right)$ (Fig. 3) and the accurate calculation of referential mean grain size (Eqs. 12 and 13). These relations simultaneously verified the applicability of the Kozeny-Carman equation for a wide range of granulometric composition, in terms of both grain 
size (samples with $D_{\mathrm{g}}$ from $1.5 \mu \mathrm{m}$ up to $6 \mathrm{~mm}$ ) and grade (Fig. 5).

\section{Results and verification}

Reliable verification of the analyzed parameter relations for a wide range of granulometric compositions was conducted using the Kozeny-Carman equation, and the analyses of the hydraulic conductivity researched deposits in situ as well as in the laboratory. Hydraulic conductivity $K\left[L T^{-1}\right]$ given by the $\mathrm{KC}$ equation (according to Eq. 6 ) is

$K=\frac{\rho g}{\mu} \frac{n_{\mathrm{e}}^{3}}{180\left(1-n_{\mathrm{e}}\right)^{2}} D_{\mathrm{m}}^{2}=0.0625 D_{\mathrm{g}}^{2} \frac{n_{\mathrm{e}}^{3}}{\left(1-n_{\mathrm{e}}\right)^{2}}$,

where $\rho\left[M L^{-3}\right]$ represents the density and $\mu\left[M L^{-1} T^{-1}\right]$ represents the viscosity of water, with gravity $g\left[L T^{-2}\right]$. The coefficient 0.0625 is correct for a diameter of the referential mean grain $D_{\mathrm{g}}$ expressed in millimeters and a water temperature of $10^{\circ} \mathrm{C}$. Hazen's (1892) non-dimensional temperature correction factor $\tau=0.70+0.03 T$ ( $T$ - temperature in ${ }^{\circ} \mathrm{C}$ ) was used to present an effect of temperature difference, ensuring an error less than $2 \%$ for $T<30^{\circ} \mathrm{C}$.

The Kozeny-Carman equation is actually a special form of Darcy's law (in the case of the unit value of hydraulic gradient). Hence, it should be applicable across all possible natural samples of porous media. The hydraulic testing of natural deposits poses a problem in correlation investigations. Non-cohesive deposits make it almost impossible to ensure the laboratory testing of the content and distribution of particles or to consolidate material in its natural and undisturbed state. The average hydraulic conductivity calculated by analyzing the pumping test data was used for correlation in the non-cohesive deposits. Test sites were chosen to fulfill the following criteria: the borehole core must be of a $100 \%$ natural lithological compound, and the analysis of particle size distribution must be conducted on the core samples. If the exploration borehole was located in the vicinity of the tested well, the hydraulic conductivity of the local scale was used. If there were more boreholes at a greater distance from the pumped well, the hydraulic conductivity of a sub-regional scale was determined and used for correlation. Values of the predicted $K$ appropriate to the test data scale, obtained from the grain size distribution analysis, were averaged. Silty and clayey samples were processed in a specific way. If a specific sample was analyzed in the laboratory (grain size analysis and hydraulic conductivity), the results were (both literally and functionally) on a laboratory scale.

The criteria for evaluating the acceptable accuracy of the predicted hydraulic conductivity, expressed by its correlation with a tested $K$ value, should not be equal for different types of materials. Chapuis and Aubertin (2003) of the École Polytechnique de Montréal conducted a very interesting study. They concluded that the acceptable accuracy of a predicted value of $K$ for clayey materials is between $1 / 3$ and 3 times the measured $K$ value, which is within the expected margin of variation for the laboratory permeability test. That relation refers to a calculation of $K$ by the Kozeny-Carman equation using a specific surface area determined in the laboratory. Such criteria can definitely be an acceptable accuracy limit for calculating the $K$ using referential grain size. In the case of silty, non-plastic soils, three specimens of the same sample may give $K$ values ranging between $1 / 2$ and 2 times the mean value. An excellent precision ( $K$ value within $\pm 20 \%$ ) can be reached with sand and gravel when the special procedure is applied (Chapuis and Aubertin, 2003). These criteria were accepted for hydraulic conductivity calculations using the KC equation and applying the effective porosity and referential mean grain size. The accepted criteria require a high level of accuracy for determining the referential mean grain size and effective porosity in their roles in Eq. (14).

In the verification process, the results acquired using the $\mathrm{KC}$ equation were matched with the results of the hydraulic tests. The average local $K$ values of sandy aquifers were identified (pumping test data) and compared to the average sample $K$ value. Verification of $K$ values for the gravelly aquifer is of a sub-regional scale because the boreholes that provided the high-quality core were located at a distance of $150-500 \mathrm{~m}$ from the pumped well. The tested value of hydraulic conductivity was determined by analyzing a series of successive steady states. The third case was of a laboratory scale where $K$ values of cohesive materials were analyzed. The hydraulic conductivity values of silty-clayey samples and the granulometric parameters were the results of the laboratory testing of each sample. The criteria for correlating predicted and tested $K$ values were customized to these procedures.

\subsection{Incohesive deposit}

The results of the calculation of hydraulic conductivity using the KC formula (Eq. 14) for individual samples of sand and gravel were presented graphically, according to borehole depths. The average values of hydraulic conductivity for individual pilot fields are presented in the tables. In this process, the arithmetic $\left(D_{\mathrm{a}}\right)$, geometric $\left(D_{\mathrm{g}}\right)$ and harmonic $\left(D_{\mathrm{h}}\right)$ forms of calculating the mean value of grain size were used.

\subsubsection{Sandy aquifer}

The hydraulic conductivities of samples from various depths are presented for four distinctive aquifers.

First, two aquifers are built of uniform, poorly graded mean- to coarse-grained sand (Fig. 6) lying at different depths. Second, two aquifers are built of well-graded fineto mean-grained sand (Fig. 7), also lying at different depths.

Table 1 gives the average difference between the predicted and tested (pumping test) hydraulic conductivities. In all cases, the overestimated value of hydraulic conductivity is a result of using the arithmetic mean grain size in calcula- 
Table 1. Average difference (\%) between predicted and tested hydraulic conductivity for sandy aquifers.

\begin{tabular}{|c|c|c|c|c|c|c|c|c|c|}
\hline & \multirow{2}{*}{$\begin{array}{l}\text { Variety of } \\
\text { equivalent } \\
\text { grain size }\end{array}$} & \multicolumn{3}{|c|}{$\begin{array}{c}\text { Diameter form grain size } \\
\text { distribution curves }\end{array}$} & \multicolumn{3}{|c|}{ Mean grain size } & \multirow[t]{2}{*}{$\begin{array}{r}\text { Tested } K_{\mathrm{t}} \\
\left(\mathrm{m} \mathrm{s}^{-1}\right)\end{array}$} & \multirow[t]{2}{*}{$\begin{array}{l}\text { Kind of } \\
\text { sand }\end{array}$} \\
\hline & & $K\left(D_{30}\right)$ & $K\left(D_{40}\right)$ & $K\left(D_{50}\right)$ & $K\left(D_{\mathrm{a}}\right)$ & $K\left(D_{\mathrm{h}}\right)$ & $K\left(D_{\mathrm{g}}\right)$ & & \\
\hline \multirow{5}{*}{$\frac{\frac{n}{0}}{\frac{0}{0}}$} & SU-1 & -16.5 & -0.1 & +14.3 & +48.5 & -9.1 & +15.8 & $2.55 \times 10^{-4}$ & Medium \\
\hline & SU-2 & -37.1 & -1.4 & +32.9 & +48.7 & -13.6 & +9.9 & $2.78 \times 10^{-4}$ & uniform \\
\hline & FS/SU-1 & -23.5 & +1.5 & +26.3 & +48.3 & -76.0 & -21.1 & $1.16 \times 10^{-4}$ & Fine to \\
\hline & FS/SU-2 & -48.8 & -27.3 & -4.9 & +38.3 & -48.9 & -12.8 & $1.40 \times 10^{-4}$ & medium \\
\hline & Average & -31.5 & -68 & +17.2 & +46.0 & -36.9 & -2.1 & & \\
\hline
\end{tabular}

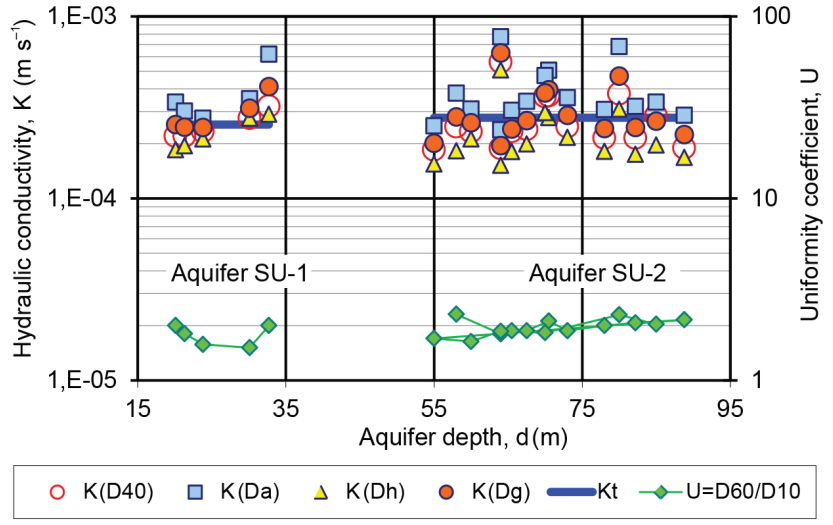

Figure 6. Predicted hydraulic conductivity calculated using the $\mathrm{KC}$ equation for samples from uniform sandy aquifer $\left(K\left(D_{40}\right)-K\right.$ calculated using effective grain size $D_{40} ; \mathrm{K}\left(D_{\mathrm{a}}\right)-K$ calculated using arithmetic mean grain size; $K\left(D_{\mathrm{h}}\right)-K$ calculated using harmonic mean grain size; $K\left(D_{\mathrm{g}}\right)-K$ calculated using geometric mean grain size; $\mathrm{Kt}$ - tested hydraulic conductivity).

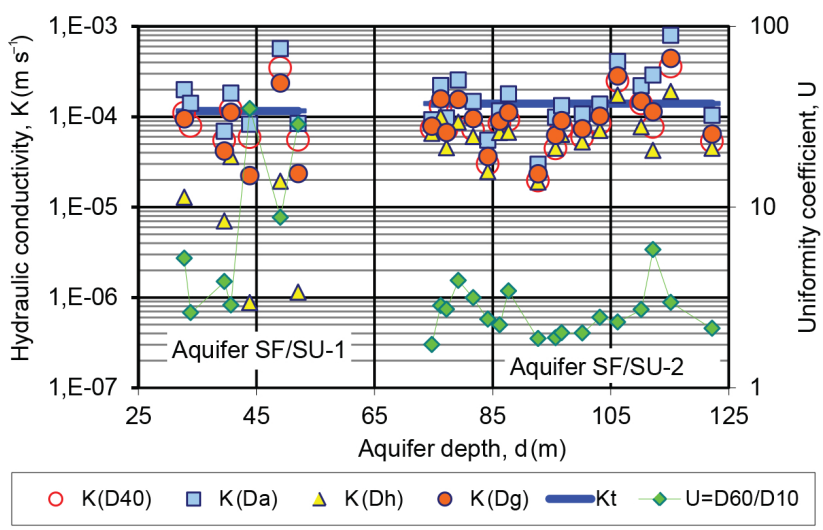

Figure 7. Predicted hydraulic conductivity calculated using the $\mathrm{KC}$ equation for samples from sandy aquifers with thin silty intercalations.

tions. The underestimated values of hydraulic conductivity are a result of using the harmonic mean grain size. The results are very close to the tested value of hydraulic conductivity because the geometric mean grain size was used in the

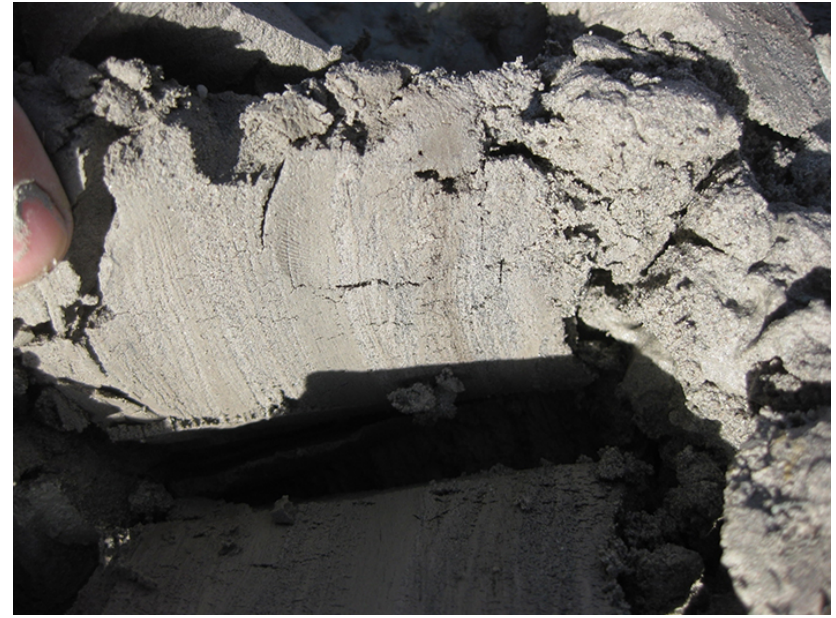

Figure 8. Fine sand sample with thin silty intercalations - test field FS/SU1 (Ravnik).

KC formula. The applicability of grain sizes according to the specific sieve size was also analyzed for median grain size value $D_{50}$ and smaller grain sizes. Using the median grain size value $\left(D_{50}\right)$ resulted in the regular overestimation of hydraulic conductivity, and using grain size $D_{30}$ regularly underestimated hydraulic conductivity (Table 1 ). An especially interesting fact is that the use of grain size $D_{40}$ (Table 1, Fig. 6) provided remarkable results with practically negligible errors.

The analyses of samples from fine sandy aquifers with silty laminas (Figs. 7-8) resulted in regularly underestimated $K$ values. The laminas of silt were so thin that it was not possible to isolate the sand content in the samples (Fig. 8).

In such specific cases, grain size $D_{40}$ or even $D_{50}$ present hydraulic properties of sandy deposits much better than the calculated mean grain size of the whole sample. Thin laminas of silt, through which the horizontal flow is negligible, have a strong impact on the grain size distribution curve. Yet, these distortions are considerably weaker if the referential geometric mean grain size $D_{\mathrm{g}}$, and not $D_{\mathrm{a}}$ or $D_{\mathrm{h}}$, is used in the calculations. 


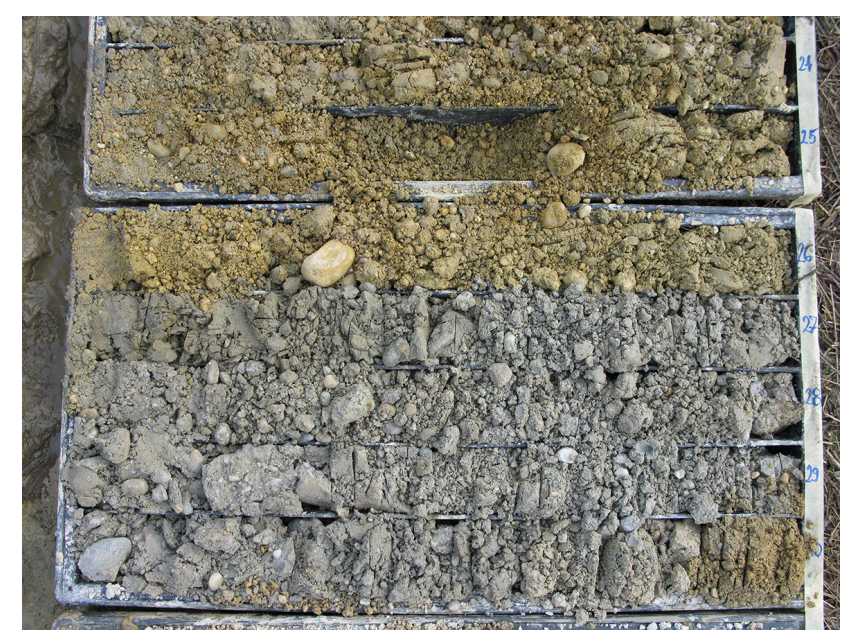

Figure 9. Gravel core from 23 to $30 \mathrm{~m}$ depth from borehole SPB-3 - test field GW (Đurđevac) (see Fig. 10a).

\subsubsection{Gravelly aquifer}

The predicted $K$ values of the gravelly aquifer were analyzed through the same procedures as those of the sandy aquifer. For clarity, only $K$ values based on $D_{\mathrm{g}}, D_{\mathrm{a}}, D_{\mathrm{h}}$ and $D_{40}$ (Table 2, Fig. 9) are presented. The extreme graduation of deposits is specific to this pilot field. These deposits contain pebbles (of diameters up to $10 \mathrm{~cm}$ ), sand and a small amount of silt (uniformity $U=D_{60} / D_{10}=17-262$ ).

A high-quality drilling core (Fig. 9) from six exploration boreholes and a particle size distribution data analysis of relevant core samples was used. All of the boreholes were scattered around the pumped well at test field GW. Borehole SPB-2 is situated on the border of the well field where a part of an aquifer of sandy development is located, and hence, the data do not correspond to a correlated average $K$ value. The predicted $K$ values of particular samples and two boreholes (SPB-3, SPB-5) mean values are presented graphically in Fig. 10. The mean predicted $K\left(D_{\mathrm{g}}\right)$ of borehole SPB-3 (Fig. 10a) is only $10 \%$ smaller than the tested value. The core quality of this borehole is presented by a core segment of depth from 23.0 to $30.0 \mathrm{~m}$ (Fig. 9).

The highest deviation of the predicted $K\left(D_{\mathrm{g}}\right)$ in relation to the tested $K_{\mathrm{t}}$ value was noted in the borehole SPB-5 core. The average $K\left(D_{\mathrm{g}}\right)$ value is $71 \%$ higher than $K_{\mathrm{t}}$ value. However, the most important fact is that the geometric mean $K\left(D_{\mathrm{g}}\right)$ of all boreholes (Table 2) in the tested area is only $5 \%$ higher than $K_{\mathrm{t}}$. Both values are of the same regional significance. Namely, $K\left(D_{\mathrm{g}}\right)$ presents (1) the result of total geometric mean size of all of the grains in the sample, (2) the hydraulic conductivity of all of the samples in the borehole and (3) all of the boreholes on the test field. The tested hydraulic conductivity $K_{\mathrm{t}}$ is identified by analyzing the series of successive cones of depression achieved in that area during the long term pumping test. Conversely, $K\left(D_{\mathrm{a}}\right)$ shows higher
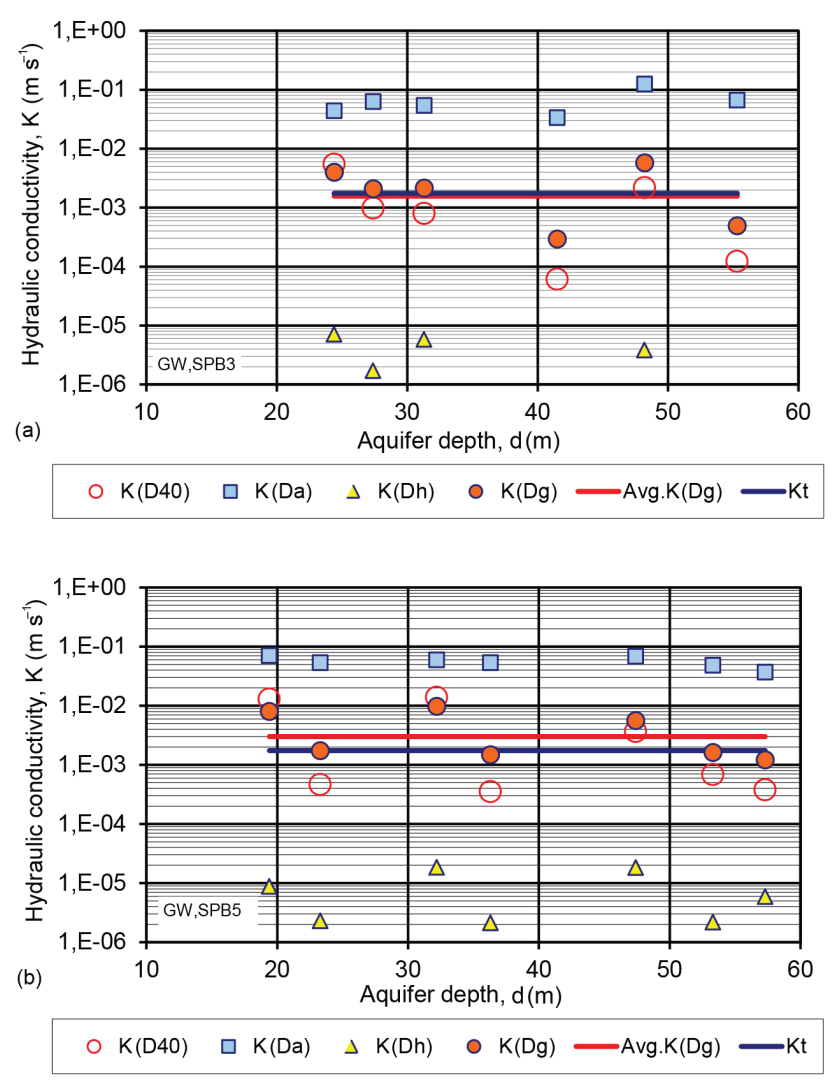

Figure 10. Predicted hydraulic conductivity calculated using the $\mathrm{KC}$ equation for samples from the gravelly aquifer (test field GW) - (a) borehole SPB-3; (b) borehole SP B-5.

values by two orders of magnitude and $K\left(D_{\mathrm{h}}\right)$ shows lower values by 3 orders of magnitude. This shows the degeneration of arithmetic algorithm for calculating mean grain size for a wide range of particle sizes.

The correlation of hydraulic conductivity mean value results for referential grain sizes $D_{\mathrm{g}}, D_{\mathrm{a}}, D_{\mathrm{h}}$ and $D_{40}$ and the tested mean hydraulic conductivity $K_{\mathrm{t}}$ on all pilot fields is presented graphically in Fig. 11a. It is clear that the values of predicted hydraulic conductivity using the referent grain size $D_{\mathrm{g}}$ closely correlate with the tested $\left(K_{\mathrm{t}}\right)$ value for all incohesive deposits, regardless of their uniformity. Using $D_{\mathrm{a}}$ and $D_{\mathrm{h}}$ results in the overestimation and the underestimation of hydraulic conductivities, respectively. This distortion significantly depends on the graduation of samples. When the sample is poorly graded, distortion was negligible. In the cases of well graded samples, distortion reaches up to a few orders of magnitude. A very high Pearson's coefficient of correlation (Fig. 11b, Table 3) confirms the closeness of tested $K_{\mathrm{t}}$ values and the predicted hydraulic conductivity $K\left(D_{\mathrm{g}}\right)$.

From a practical point of view, an interesting fact is that very good results are achieved using grain size $D_{40}$ (Fig. 11a). 
Table 2. Average predicted hydraulic conductivity $K\left(\mathrm{~m} \mathrm{~s}^{-1}\right)$ for boreholes in the gravelly aquifer (test field GW).

\begin{tabular}{|c|c|c|c|c|c|c|c|c|c|}
\hline \multirow{2}{*}{$\begin{array}{l}\text { Bore- } \\
\text { hole }\end{array}$} & \multicolumn{2}{|c|}{$K\left(D_{\mathrm{g}}\right)$} & \multicolumn{2}{|c|}{$K\left(D_{\mathrm{a}}\right)$} & \multicolumn{2}{|c|}{$K\left(D_{\mathrm{h}}\right)$} & \multicolumn{2}{|c|}{$K\left(D_{40}\right)$} & \multirow{2}{*}{$\begin{array}{c}\text { Tested } K_{\mathrm{t}} \\
\left(\mathrm{m} \mathrm{s}^{-1}\right)\end{array}$} \\
\hline & Geom. & Aritm. & Geom. & Aritm. & Geom. & Aritm. & Geom. & Aritm. & \\
\hline SPB-1 & $2.5 \times 10^{-3}$ & $3.5 \times 10^{-3}$ & $5.5 \times 10^{-2}$ & $5.8 \times 10^{-2}$ & $6.6 \times 10^{-6}$ & $8.7 \times 10^{-6}$ & $1.1 \times 10^{-3}$ & $2.4 \times 10^{-3}$ & \\
\hline SPB-3 & $1.6 \times 10^{-3}$ & $2.5 \times 10^{-3}$ & $5.9 \times 10^{-2}$ & $6.4 \times 10^{-2}$ & $2.2 \times 10^{-6}$ & $3.3 \times 10^{-6}$ & $6.4 \times 10^{-4}$ & $1.6 \times 10^{-3}$ & \\
\hline SPB-4 & $1.3 \times 10^{-3}$ & $2.2 \times 10^{-3}$ & $4.3 \times 10^{-2}$ & $4.9 \times 10^{-2}$ & $1.4 \times 10^{-6}$ & $1.8 \times 10^{-6}$ & $5.1 \times 10^{-4}$ & $1.1 \times 10^{-3}$ & \\
\hline SPB-5 & $3.0 \times 10^{-3}$ & $4.2 \times 10^{-3}$ & $5.5 \times 10^{-2}$ & $5.6 \times 10^{-2}$ & $5.7 \times 10^{-6}$ & $8.3 \times 10^{-6}$ & $1.6 \times 10^{-3}$ & $4.6 \times 10^{-3}$ & $1.8 \times 10^{-3}$ \\
\hline SPB-6 & $1.2 \times 10^{-3}$ & $1.4 \times 10^{-3}$ & $2.6 \times 10^{-2}$ & $2.8 \times 10^{-2}$ & $2.2 \times 10^{-6}$ & $2.4 \times 10^{-6}$ & $7.1 \times 10^{-4}$ & $8.8 \times 10^{-4}$ & \\
\hline Aver. & $1.8 \times 10^{-3}$ & $2.6 \times 10^{-3}$ & $2.9 \times 10^{-1}$ & $4.9 \times 10^{-2}$ & $3.1 \times 10^{-6}$ & $4.0 \times 10^{-6}$ & $8.4 \times 10^{-4}$ & $1.8 \times 10^{-3}$ & \\
\hline$K / K_{\mathrm{t}}$ & 1.02 & 1.47 & 163 & 28 & 0.0017 & 0.0023 & 0.48 & 1.01 & \\
\hline
\end{tabular}

Table 3. Numerical results of correlations between tested $K_{\mathrm{t}}$ and predicted $K$ for samples from test fields in Croatia (CRO) and USGS laboratory.

\begin{tabular}{llllcccc}
\hline Samples from & Materials & \multicolumn{3}{l}{ Referential } & \multicolumn{4}{c}{ Pearson's correlation coefficients } \\
& & mean grain & Mark & Nominal values & Log values \\
& & size & & $R$ & $R^{2}$ & $R$ & $R^{2}$ \\
\hline CRO test fields & Gravel, sand & $D_{\mathrm{g}}$ & $R_{1}$ & 0.999 & 0.998 & 0.988 & 0.976 \\
& Gravel, sand & $D_{40}$ & $R_{2}$ & 1.000 & 1.000 & 0.995 & 0.991 \\
\hline Together CRO + USGS lab. & Gravel, sand & $D_{\mathrm{g}}$ & $R_{3}$ & 0.997 & 0.994 & 0.993 & 0.985 \\
\hline CRO test fields & Silt, clay & $D_{\mathrm{g}}$ & $R_{4}$ & 0.740 & 0.547 & 0.834 & 0.696 \\
& Gravel, sand, silt, clay & $D_{\mathrm{g}}$ & $R_{5}$ & 1.000 & 0.999 & 0.971 & 0.942 \\
\hline All together CRO + USGS lab. & Gravel, sand, silt, clay & $D_{\mathrm{g}}$ & $R_{6}$ & 0.997 & 0.995 & 0.985 & 0.971 \\
\hline
\end{tabular}

\subsection{Cohesive deposit}

The validities of the aquitard's predicted $K$ values were analyzed for 86 samples using the geometric $\left(D_{\mathrm{g}}\right)$, arithmetic $\left(D_{\mathrm{a}}\right)$ and harmonic $\left(D_{\mathrm{h}}\right)$ mean grain sizes. The results of the correlation between the predicted and laboratorytested hydraulic conductivities for the samples of cohesive deposits are presented in Fig. 12a. The permeability test and grain size analysis were performed for each individual sample. The samples were of various compounds of silty and clayey materials, and their tested hydraulic conductivities have a wide range, exceeding three orders of magnitude (between $10^{-11}$ and $10^{-7} \mathrm{~m} \mathrm{~s}^{-1}$ ). This wide range ensures reliable graphical and numerical correlations. These results are similar to the results of previously explained analyses of non-cohesive deposits. The arithmetic mean grain sizes result in overestimating $K\left(D_{\mathrm{a}}\right)$, and the harmonic mean grain sizes result in underestimating $K\left(D_{\mathrm{h}}\right)$ (that is, average $K\left(D_{\mathrm{a}}\right) / K_{\mathrm{t}}$ equaled 14.5 and $K\left(D_{\mathrm{h}}\right) / K_{\mathrm{t}}$ equaled 0.17$)$. Good results were achieved using the referential geometrical mean grain size, and the predicted values of hydraulic conductivity $K\left(D_{\mathrm{g}}\right)$ were very close to the tested value $K_{\mathrm{t}}$ (within the set limits of the accuracy criteria).

The graphical correlation (Fig. 12b) illustrates concentrated $K\left(D_{\mathrm{g}}\right)$ values in the neighborhood of the tested value $K_{\mathrm{t}}$, and most of the results are within the range $1 / 3 K_{\mathrm{t}}<K\left(D_{\mathrm{g}}\right)<3 K_{\mathrm{t}}$. The numerical correlation confirms their high correlativity, $R^{2}=0.696$. This is a very high value, especially considering the fact that some of the deviations may be the result of an error in conducting the laboratory permeability test. The achieved results confirm earlier conclusions that the total geometric mean grain diameter $D_{\mathrm{g}}$ truly represents the referent mean grain size of the silty-clayey deposits. Additionally, it was used as a reliable reference point for the verification of the porosity curve $n_{\mathrm{e}}=f\left(D_{\mathrm{g}}\right)$, presented in Fig. 5.

\section{Discussion}

The Kozeny-Carman equation was limited to only calculating the hydraulic conductivity of incohesive materials (Kasenow, 1997, 2010). Additionally, the use of the KC equation for calculating the hydraulic conductivities of cohesive materials using particle size has been frequently disputed in numerous papers and reports. The reasons include varied particle size, high proportions of fine fractions in deposits (Young and Mulligan, 2004), electrochemical reaction between the soil particles and water and large content of particles such as mica (Carrier, 2003). All of these factors also affect the effective porosity, and some of them also affect the mean grain size. Is the effect of the aforementioned factors incorporated (and if so, how much) in the size and distribution of effective porosities and referential mean grain sizes? 

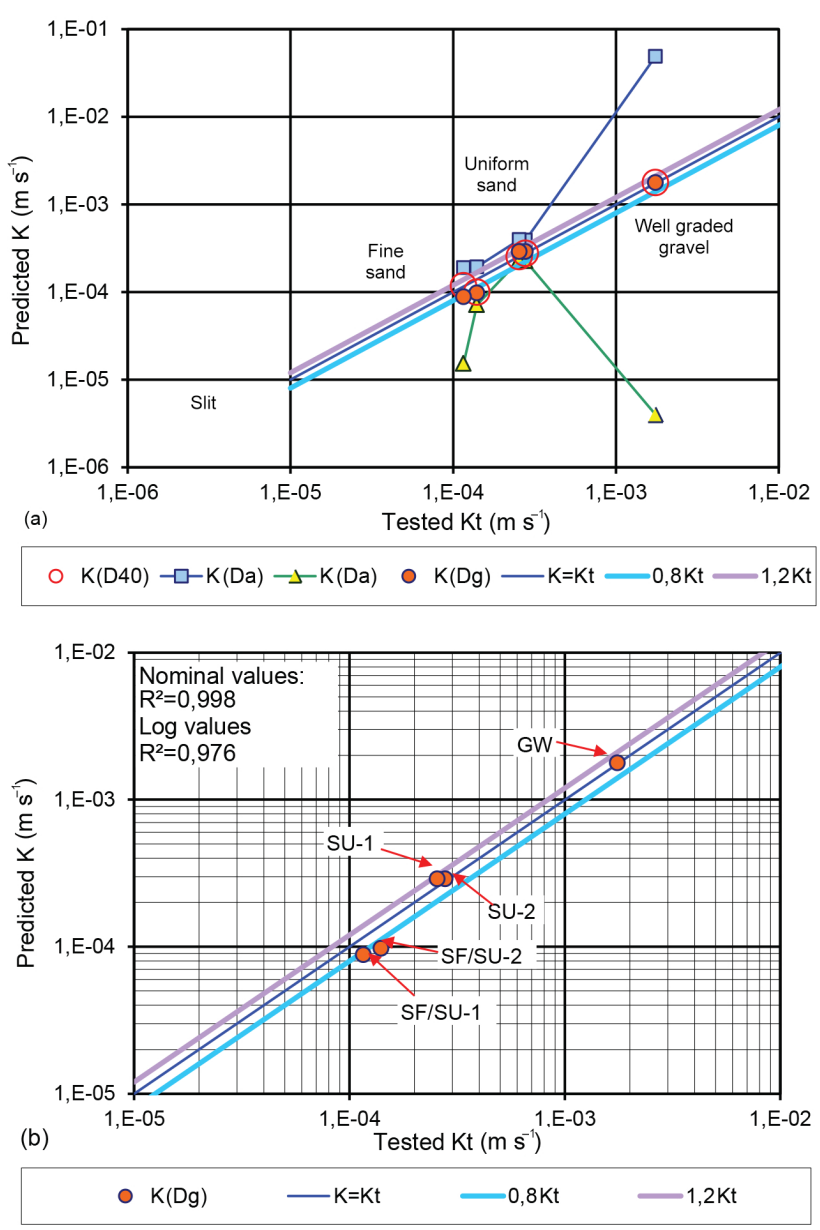

Figure 11. Graphical correlation between predicted $K$ and tested $K_{\mathrm{t}}$ for sandy and gravelly aquifers. (a) Difference between arithmetic, geometric and harmonic mean grain size. (b) Results of correlation between predicted $K\left(D_{\mathrm{g}}\right)$ and tested $K_{\mathrm{t}}$.

The conducted analyses, as graphically summarized in Fig. 13, confirmed that the use of (1) geometric mean as a referent mean grain size (Eqs. 12 or 13) and (2) effective porosity according to Fig. 5 in the Kozeny-Carman equation forms a model of flow through the porous media. This model is valid for various soil materials and mixtures with a wide range of hydraulic conductivity values (from $10^{-12} \mathrm{~m} \mathrm{~s}^{-1}$ up to $10^{-2} \mathrm{~m} \mathrm{~s}^{-1}$ ). The use of the arithmetic mean $D_{\mathrm{a}}$ and the harmonic mean $D_{\mathrm{h}}$ results in the overestimation and the underestimation, respectively, of the value of hydraulic conductivity. The overestimated porosity is followed by the overestimated value of hydraulic conductivity. This can have a huge impact on predicting the hydraulic conductivity of clayeysilty deposits, which are of very high total porosity but very low effective porosity. Therefore, the use of total instead of effective porosity in Eq. (14) can lead to a misunderstanding regarding the validity of the harmonic mean grain size for calculating the hydraulic conductivities of cohesive materials.
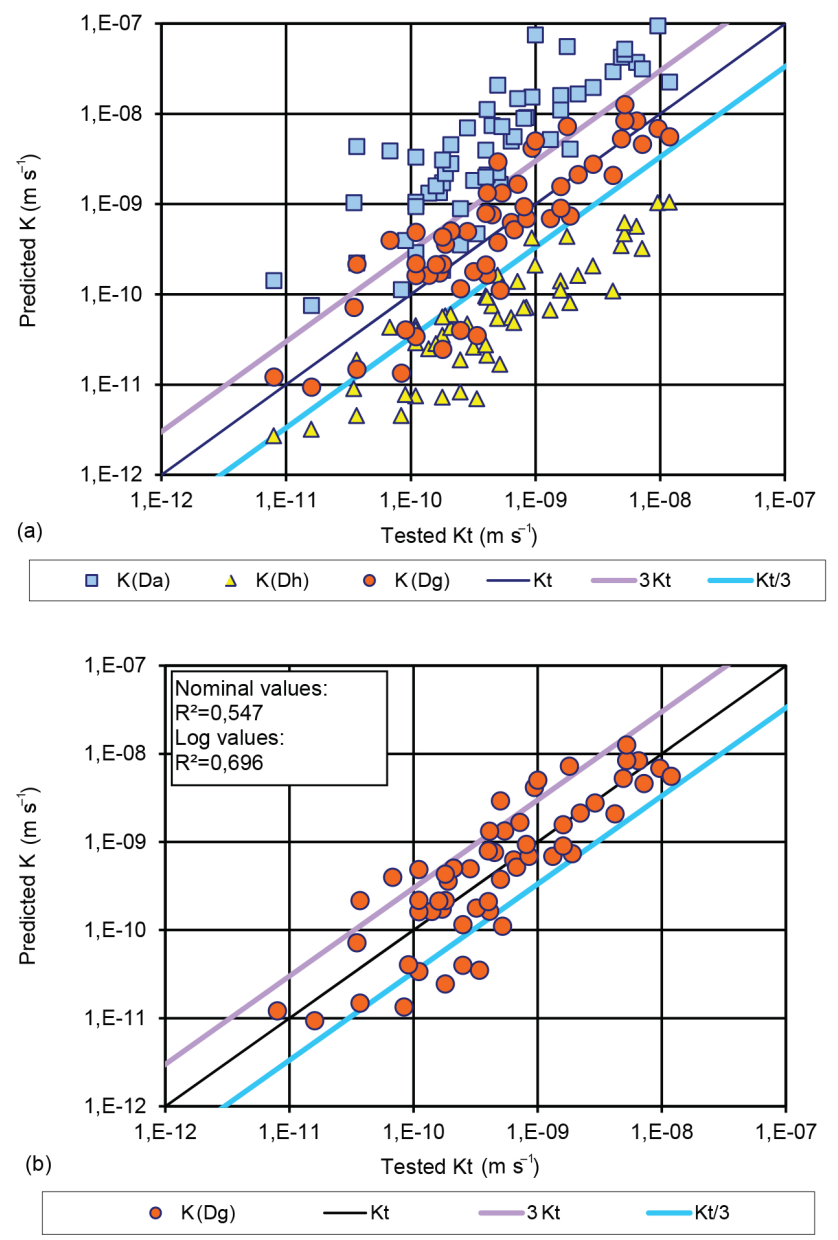

Figure 12. Graphical correlation between predicted $K$ and tested $K_{\mathrm{t}}$ for silt and clay deposits. (a) Difference between arithmetic, geometric and harmonic mean grain size. (b) Result of correlation between predicted $K\left(D_{\mathrm{g}}\right)$ and tested $K_{\mathrm{t}}$.

Pearson's correlation analysis was conducted for the numerical and logarithmic values of predicted hydraulic conductivities $K\left(D_{\mathrm{g}}\right)$ of all of the samples, grouped in three basic data groups (Table 3). These include non-cohesive materials (gravel and sand), cohesive materials (silt and clay) and the group of all of the analyzed samples. The verification of the results for the non-cohesive materials group was conducted for eight more samples from the USGS laboratory (Morris and Johnson, 1967). The verification of the results for cohesive materials was conducted by the analyses of two more samples from the USGS laboratory. The correlation results of all of the $K\left(D_{\mathrm{g}}\right)$ are presented in Fig. 14.

A separate sub-group was formed by the non-cohesive material data from all five CRO test fields by using the referent grain size $D_{40}$. This correlation results in very high correlation coefficients. The lowest values of the correlation coefficients were observed for the silty-clayey materials group, but their values (in Table 3 ) certainly confirm the validity of 


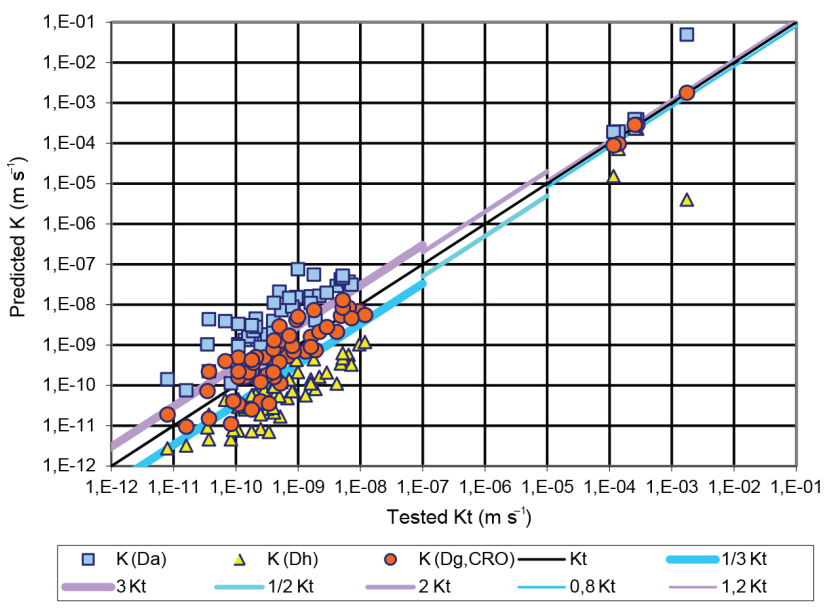

Figure 13. Relation between of effects of mean grain size $D_{\mathrm{a}}, D_{\mathrm{g}}$ and $D_{\mathrm{h}}$ on predicted hydraulic conductivity for all analyzed samples.

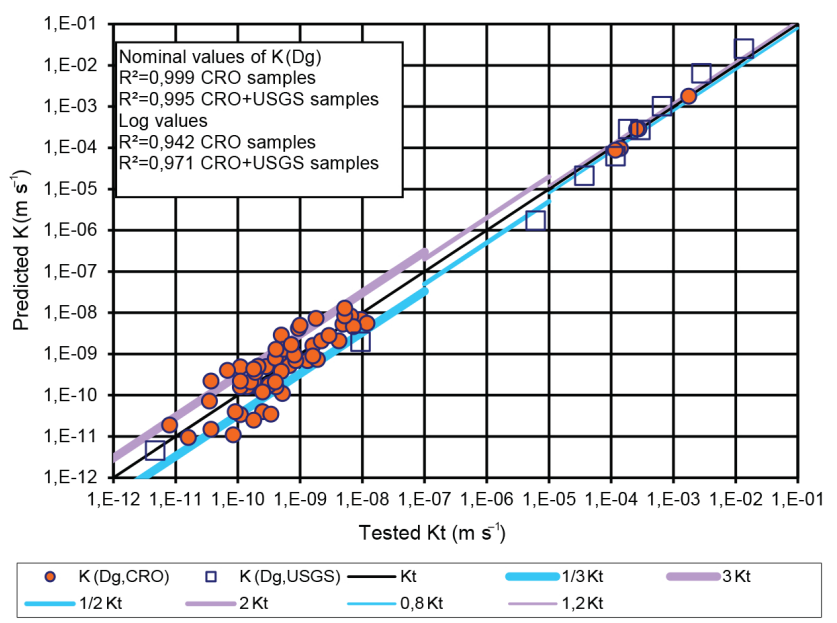

Figure 14. Verification of graphical and numerical correlation between the tested $K_{\mathrm{t}}$ and the predicted hydraulic conductivity $K\left(D_{\mathrm{g}}\right)$ using referential geometric mean size for all samples.

the observed relations. It is very important to note that the test data used in this research refer to standard, serial tests and that specific tests may potentially result in even stronger correlations.

The graphical correlation between the tested and the predicted hydraulic conductivities (Fig. 14) illustrates the universality of the $\mathrm{KC}$ model (when applying referential mean grain size $D_{\mathrm{g}}$ and an effective porosity $n_{\mathrm{e}}$ ) in a wide range of flow conditions. The very high values of correlation coefficients $R^{2}$ (Table 3 ) confirm the relations in continuous porous media conditions on a laboratory scale.

\section{Conclusions}

The following conclusions can be drawn from this study:

1. The geometric mean size of all particles contained in the sample $D_{\mathrm{g}}$ unambiguously affects the permeability and specific surface area of cohesive and non-cohesive deposits, regardless of the grain size and distribution of specific particles. Hence, $D_{\mathrm{g}}$ represents the referential grain size of the sample.

2. The distribution of effective porosities in functions of the referential grain size $n_{\mathrm{e}}=f\left(D_{\mathrm{g}}\right)$ is presented graphically for all types of clastic deposits. The graph was constructed following previously reported data and was calibrated according to the congruence between the tested hydraulic conductivity and its predicted value calculated by applying the Kozeny-Carman equation. Thus, this effective porosity presents the flow porosity and is slightly lower than the specific yield commonly referred to in the literature.

3. The successful application of the KC flow model confirms its validity in a range of hydraulic conductivities between $10^{-12}$ and $10^{-2} \mathrm{~m} \mathrm{~s}^{-1}$. Simultaneously, the value of effective porosity and its relative referential grain size $D_{\mathrm{g}}$ in a range of $1.5 \mu \mathrm{m}$ to $6 \mathrm{~mm}$ has been verified. It can be concluded that, through the presented parameters, the range of applying the Kozeny-Carman model for calculating permeability and specific surface area is extended up to the limits of Darcy's law validity.

4. The value of the referent mean grain size in cases of analyzed non-cohesive samples is very close to the value of the grain size $D_{40}$ (read from grain size distribution curve).

Acknowledgements. The authors would like to thank Željka Brkić, Željko Miklin and Ivana Žunić Vrbanek for their perseverance and help in collecting large amounts of laboratory data used in this study. This study was supported by the Ministry of Science, Education and Sports of the Republic of Croatia (Basic Hydrogeological Map of the Republic of Croatia 1:100000-basic scientific project of the Croatian Geological Survey).

Edited by: A. Guadagnini 


\section{References}

Al-Tabbaa, A. and Wood, D.: Some measurements of the permeability of kaolin, Geotechnique, 37, 499-503, 1987.

Arkin, H. and Colton, R.: Statistical metods, 4th edn., Barnes and Noble Inc, New York, USA, 1956.

Bear, J.: Dyinamics of Fluid in Porous Media, Elsevier, New York, USA, 1972.

Blake, F. C.: The resistance of packing to fluid flow, T. Am. Inst. Chem. Eng., 14, 415-421, 1922.

Brkić, Ž., Larva, O., and Urumović, K.: The quantitative status of groundwater in alluvial aquifers in norther Croatia, in: Journal of the Croatian Geological Survey and the Croatian Geological Society, edited by: Horvat, M., Geol. Croat., 63, 283-298, 2010.

Carman, P. C.: Fluid flow through granular beds, Transactions, 150166, 1937.

Carman, P. C.: Permeability of saturated sand, soil and clay, J. Agr. Sci., 29, 263-273, 1939.

Carrier, W. D.: Goodbye, Hazen; Hello, Kozeny-Carman, J. Geotech. Geoenviron., 129, 1054-1056, 2003.

Chapuis, R. P. and Aubertin, M.: Predicting the coefficient of permeability of soils using the Kozeny-Carman equation, Montreal: Département des génies civil, géologique et des mines, École Polytechnique de Montréal, Montréal, Canada, 2003.

Cheng, C. and Chen, X.: Evaluation of methods for determination of hydraulic properties on an aquifer-aquitard system hydrologically connected to river, Hydrogeol. J., 669-678, 2007.

Davis, S. N. and De Wiest, R. J.: Hydrogeology, John Wiley and Sons, New York, USA, 1966.

Dolinar, B. and Otoničar, M.: Evaluation of permeability of saturated clays based on their physical properties, Geologija, 50, 487-495, 2007.

Eckis, R.: South Coastal Basin investigation, geology, and ground water storage capacity of valley fill, California Division of Water Resources Bulletin, Sacramento, CA, USA, 45, 91-246, 1934.

Fair, G. and Hatch, L.: Fundamental factors governing the streamline flow of water through sand, J. Am. Water Works Ass., 18, 1551-1565, 1933.

Hantush, M. S.: Hydraulics of wells, Academic Press, New York, USA, 1964.

Hazen, A.: Some Physical Properties of Sands and Gravels, With Special Rreference to Their Use in Filtration, Massachusetts State Board of Health, Boston, MA, USA, 1892.

Hubbert, M. K.: Darcy's law and the field equations of the flow of underground fluids, Petroleum Transactions, AIME, 222-239, 1956.

Irani, R. and Callis, C.: Particle Size: Measurement, Interpretation and Application, John Wiley and Sons, New York, USA, 1963.
Irmay, S.: On the hydraulic conductivity of unsaturated soils, Transcactions, EOS Trans. AGU, Washington, DC, USA, 35, 463467, 1954.

Kamann, P. J., Ritzi, R. W., David, D. F., and Conrad, C. M.: Porosity and Permeability in Sediment Mixtures, Groundwater, 45, 429-438, 2007.

Kasenow, M.: Applied ground-water hydrology and well hydraulics, Water Resources Publications LLC, Highlands Ranch, CO, USA, 1997.

Kasenow, M.: Determination of hydraulic conductivity from grain size analysis, Water Resources Publications LLC, Highlands Ranch, CO, USA, 2010.

Koltermann, C. E. and Gorelick, S. M.: Fractional packing model for hydraulic conductivity derived from sediemnt mixtures, Water Resour. Res., 3283-3297, 1995.

Kovács, G.: Seepage hydraulics, Elsevier Science Publishers, Amsterdam, the Netherlands, 1981.

Kozeny, J.: Über Kapillare Leitung des Wassers im Boden, Sitzungsber. Akad. Wiss., Vienna, Austria, 271-306, 1927.

Krüger, F.: Die Grundwasserbewegung, Internationale Mitteilungen für Bodenkunde, 8, p. 105, 1918.

Mavis, F. T. and Wilsey, E. F.: A study of the permeability of sand, State University of Iowa, Iowa City, IA, USA, 1936.

Morris, D. and Johnson, A.: Summary of Hydrologic and Physical Properties of Rock and Soil Materials, as Analyzed by the Hydrologic Laboratory of US Geological Survey 1948-1960, US Geological Survey, Washington, USA, 1967.

Odong, J.: Evaluation of Empirical Formulae for Determination of Hodraulic Conductivity based on Grain-Size Analysis, The Journal of American Science, 4, 1-6, 2008.

Slichter, C. S.: The Motions of Underground Waters (Water Supply and Irrigation Paper), US Geological Survey, 1902.

Todd, D. K.: Ground Water Hydrology, John Wiley and Sons, New York, USA, 1959.

Urumović, K.: Parameter quantification of clastic sediments hydrogeologic properties based on test fields in northern Croatia. Dissertation, unpubl., Univrsity of Zagreb, Zagreb, Croatia, RGNf, 164, 2013.

Urumović, S. K.: Physical Principles of Groundwater Dynamics, Faculty of Mining, Geology and Oil Engineering, Zagreb, Croatia, 2003 (in croatian).

Vukovic, M. and Soro, A.: Determination of hydraulic conductivity of porous media from grain size composition, Water Resources Publicationsm Littleton, CO, USA, 1992.

Young, R. N. and Mulligan, C. N.: Natural Attenuation of Contaminants in Soils, Lewis Publishers, Boca Raton, FL, USA, 2004.

Zunker, F.: Das allgemeine Grundwasserfließgesetz, J. Gasbel. u. Wasserversorg., 63, p. 332, 1920. 